\title{
MicroRNA-320 was downregulated in non-small cell lung cancer and inhibited cell proliferation, migration and invasion by targeting fatty acid synthase
}

\author{
TING LEI ${ }^{1 *}$, YUNTAO ZHU $^{2 *}$, CHUANFU JIANG ${ }^{2}$, YU WANG $^{1}$, \\ JUNFENG FU $^{1}, \mathrm{ZHE} \mathrm{FAN}^{1}$ and HAIMING QIN ${ }^{3}$ \\ ${ }^{1}$ Department of Thoracic Surgery, The Second Affiliated Hospital of Dalian Medical University; \\ ${ }^{2}$ Department of Thoracic Surgery, The First Affiliated Hospital of Dalian Medical University, Dalian, Liaoning 116011; \\ ${ }^{3}$ Department of Pathology, General Hospital of Shenyang Military Area Command \\ of Chinese PLA, Shenyang, Liaoning 110016, P.R. China
}

Received July 4, 2015; Accepted April 28, 2016

DOI: $10.3892 / \mathrm{mmr} .2016 .5370$

\begin{abstract}
The expression and functions of microRNA (miR)-320 have been previously investigated in various types of cancer. However, to the best of our knowledge, no previous studies have investigated miR-320 in human lung cancer. The current study determined the expression, biological functions and molecular mechanisms of miR-320 in human lung cancer. The expression level of miR-320 in human non-small cell lung cancer (NSCLC) and normal adjacent tissue samples (NATs), NSCLC cell lines and non-tumorigenic bronchial epithelial cells was measured by reverse transcription-quantitative polymerase chain reaction. Following transfection with miR-320 mimics, 3-(4,5-dimethylthiazol-2-yl)-2,5-diphenyltetrazolium bromide, cell migration and cell invasion assays, western blot analysis and luciferase assay were performed in human NSCLC cell lines. The results demonstrated that miR-320 was significantly downregulated in NSCLC tissue samples and cell lines compared with NATs and a control cell line, respectively. Statistical analysis demonstrated that expression of miR-320 was significantly associated with the TNM classification and metastasis. It was also observed that miR-320 inhibited cell growth, migration and invasion in NSCLC cells. Additionally, the present study provided evidence that miR-320 may directly target fatty acid synthase. These results suggest that miR-320 may serve as a therapeutic biomarker of NSCLC in the future.
\end{abstract}

Correspondence to: Professor Haiming Qin, Department of Pathology, General Hospital of Shenyang Military Area Command of Chinese PLA, 83 Wenhua Road, Shenyang, Liaoning 110016, P.R. China

E-mail: pro_haimingqin@163.com

${ }^{*}$ Contributed equally

Key words: non-small cell lung cancer, microRNA-320, metastasis, fatty acid synthase

\section{Introduction}

Lung cancer is the leading cause of cancer-associated mortality worldwide (1). In the United States, it was estimated that there would be 221,200 new cases and 158,040 mortalities caused by lung cancer in 2015 (2). The occurrence and progression of lung cancer is complex and associated with various signaling pathways. Its incidence and mortality are increasing each year as a result of environmental pollution, particularly in China (3). Lung cancer can be divided into two clinically relevant subtypes: Small cell lung cancer (SCLC) and non-small cell lung cancer (NSCLC) (4). NSCLC, as the predominant form of lung cancer, accounts for $80-85 \%$ of all cases of lung cancer (5). Large cell carcinoma, adenocarcinoma, squamous carcinoma and adenosquamous carcinoma are types of NSCLC (6). Patients with NSCLC are often diagnosed in the late stages when it is locally advanced or has metastasized, rendering it one of the most lethal forms of cancer (7). Although there has been progress regarding early detection and treatment by radical surgical resection combined with chemotherapy and radiation therapy, the prognosis of patients with NSCLC remains poor and the 5-year survival rate is $\leq 15 \%(8,9)$. Thus, it is important to develop novel strategies and therapeutic targets for the treatment of NSCLC.

Increasing evidence has indicated that microRNAs (miRNAs) are deregulated in lung cancer (10-12). miRNAs are a type of endogenous non-protein-coding short RNA (19-22 nucleotides in length) that are widely expressed in eukaryotes (13). miRNAs are critical for the regulation of various diverse physiological and pathological processes, including proliferation, cell death, cell cycle, migration, invasion, development and differentiation. miRNAs function via complementary base pairing with target mRNAs in the $3^{\prime}$ untranslated region (3' UTR), leading to cleavage or translation repression of the mRNA (14-16). Previous studies have demonstrated that more than half of miRNAs are located in cancer-associated genomic regions, suggesting that aberrant expression of miRNAs may be important during tumorigenesis and progression (17). miRNAs are stable molecules and may be useful for cancer diagnosis, 
treatment and predicting prognosis $(18,19)$. miRNAs have previously been demonstrated to function as oncogenes or tumor suppressors, and are aberrantly expressed in various types of human malignancy (20). Thus, investigating miRNAs may be critical to elucidate the prognostic value and therapeutic potential of miRNAs in lung cancer.

miRNA (miR)-320 has previously been reported to be frequently downregulated in multiple types of cancer. However, to the best of our knowledge, the expression, biological functions and molecular mechanisms of miR-320 in NSCLC have not been investigated. Thus, the aim of the present study was to elucidate the expression, biological functions and molecular mechanisms of miR-320 in NSCLC.

\section{Materials and methods}

Clinical specimens. The procedures were approved by the Ethic Committee on Human Experimentation of The First Affiliated Hospital of Dalian Medical University (Dalian, China) and written informed consent was also obtained from each patient. Samples of primary cancer tissue $(n=81)$ and paired normal adjacent tissue (NAT) were obtained from patients who had undergone surgery at The First Affiliated Hospital of Dalian Medical University. None of the patients had been treated with radiotherapy or chemotherapy prior to surgery. All samples were rapidly placed in liquid nitrogen and stored at $-80^{\circ} \mathrm{C}$ until use. The clinical data of NSCLC patients are presented in Table I.

Cell culture and transfection. NSCLC cell lines H23, H522 and non-tumorigenic bronchial epithelium BEAS-2B cells were obtained from American Type Culture Collection (Manassas, VA, USA). H23 and H522 cells were cultured in RPMI-1640 medium (Gibco; Thermo Fisher Scientific, Inc., Waltham, MA, USA) supplemented with $10 \%$ fetal bovine serum (FBS), $100 \mathrm{U} / \mathrm{ml}$ penicillin and $100 \mathrm{mg} / \mathrm{ml} \mathrm{streptomycin}$ (Gibco; Thermo Fisher Scientific, Inc.) in a cell incubator at $37^{\circ} \mathrm{C}$ with an atmosphere of $5 \% \mathrm{CO}_{2}$. BEAS-2B cells were cultured in LHC-9 medium (Gibco; Thermo Fisher Scientific, Inc.) containing $10 \%$ FBS.

Mature miR-320 mimics (5'-AGCGGGAGAGUUGGGUCGAAAA-3'), miRNA mimics negative control (NC; 5'-UUCUCCGAACGUGUCACGUTT-3'). and the luciferase reporter plasmid were obtained from Shanghai GenePharma Co., Ltd. (Shanghai, China). H23 and H522 were transfected with miR-320 mimics, NC or co-tranfected with luciferase reporter plasmid using Lipofectamine 2000 (Invitrogen; Thermo Fisher Scientific, Inc.) according to the manufacturer's protocol.

$R N A$ isolation and reverse transcription-quantitative polymerase chain reaction ( $R T-q P C R)$. Total RNA was extracted from the tumor tissues, NATs and cells using TRIzol reagent (Invitrogen; Thermo Fisher Scientific, Inc.) following the manufacturer's protocol. Then, PrimeScript reverse transcription-PCR kit (Takara Biotechnology Co., Ltd., Dalian, China) was used to perform RT to obtain cDNA. For analysis of miR-320 expression levels, a SYBR PrimeScript miRNA RT-PCR kit (Takara Biotechnology Co., Ltd.) was used with the ABI 7500 Real-Time PCR detection system (Applied
Biosystems; Thermo Fisher Scientific, Inc.), with U6 serving as the internal control. Each sample was analyzed in triplicate. Primers were synthesized by Guangzhou RiboBio Co., Ltd. (Guangzhou, China). Data were analyzed using the $\Delta \Delta \mathrm{Cq}$ method (21)

Cell proliferation assay. The effect of miR-320 on NSCLC cell proliferation was analyzed using a 3-(4,5-dimethylthiazol-2-yl)-2,5-diphenyltetrazolium bromide (MTT) assay. Transfected cells (miR-320 or NC) were seeded in 96-well plates at a density of 3,000 cells/well in $100 \mu \mathrm{l}$ medium. MTT assay was performed every $24 \mathrm{~h}$ for $120 \mathrm{~h}$ following transfection. Briefly, $20 \mu \mathrm{l}$ MTT $(5 \mathrm{mg} / \mathrm{ml}$; Sigma-Aldrich, St. Louis, MO, USA) was added into each well and cells were incubated for $4 \mathrm{~h}$ at $37^{\circ} \mathrm{C}$. Subsequently, the formazan was dissolved in $200 \mu 1$ dimethyl sulfoxide. The absorbance at $490 \mathrm{~nm}$ was measured using a microplate reader (ELx800; Bio-Tek Instruments, Inc., Winooski, VT, USA). For each treatment group wells were assessed in triplicate.

Cell migration and invasion assay. The migration and invasion ability of NSCLC cells transfected with miR-320 mimics and $\mathrm{NC}$ was analyzed using Transwell chambers with an $8-\mu \mathrm{m}$ pore polycarbonate membrane (EMD Millipore, Billerica, MA, USA). For cell migration assays, $2 \times 10^{4}$ transfected cells in $100 \mu \mathrm{l}$ serum-free RPMI-1640 medium were placed into the upper chambers. A volume of $500 \mu 1$ RPMI-1640 medium supplemented with $20 \%$ FBS was added into the lower chambers. The cell invasion assays were performed according to the same procedure, although the Transwell chambers were pre-coated with Matrigel (BD Biosciences, San Jose, CA). Subsequent to incubation (12 $\mathrm{h}$ for migration assay and $24 \mathrm{~h}$ for invasion assay), cells that did not migrate or invade through the pores were carefully wiped away with cotton wool. Subsequently, the inserts were fixed with $100 \%$ methanol for $10 \mathrm{~min}$, and stained with $0.5 \%$ crystal violet (Beyotime Institute of Biotechnology, Haimen, China) and imaged with an inverted microscope (IX71; Olympus Corporation, Tokyo, Japan) at x200 magnification.

Bioinformatics analysis. The target gene information of miR-320 was analyzed using Targetscan (www.targetscan. org/).

Western blotting. To determine the expression level of fatty acid synthase (FAS) at the protein level, western blot analysis was performed. Protein samples of the transfected cell lines were harvested using radioimmunoprecipitation assay lysis buffer (Beyotime Institute of Biotechnology) containing protease inhibitors and phosphatase inhibitors (Roche Diagnostics, Basel, Switzerland). Protein concentrations $(30 \mu \mathrm{g})$ were measured by a bicinchoninic acid assay kit (Nanjing KeyGen Biotech Co., Ltd., Nanjing, China). Briefly, equal quantities of protein lysates were separated by $10 \%$ SDS-polyacrylamide gel electrophoresis for $20 \mathrm{~min}$ at $70 \mathrm{~V}$ and transferred to polyvinylidene fluoride membrane (EMD Millipore). After blocking with 5\% non-fat milk Tris-buffered saline solution containing $0.1 \%$ Tween 20 , and incubated with primary antibodies overnight at $4^{\circ} \mathrm{C}$.

Primary antibodies in the current study included mouse anti-FAS monoclonal antibody (1:1,000 dilution; cat 
Table I. A comparison of microRNA-320 expression in non-small cell lung cancer and clinicopathological features.

\begin{tabular}{|c|c|c|c|c|}
\hline \multirow[b]{2}{*}{ Clinical features } & \multirow[b]{2}{*}{ Cases, $\mathrm{n}$} & \multicolumn{2}{|c|}{ miR-320 expression } & \multirow[b]{2}{*}{ P-value } \\
\hline & & Low & High & \\
\hline Gender & & & & 0.812 \\
\hline Male & 38 & 30 & 8 & \\
\hline Female & 43 & 33 & 10 & \\
\hline Age, years & & & & 0.544 \\
\hline$<60$ & 49 & 37 & 12 & \\
\hline$\geq 60$ & 32 & 26 & 6 & \\
\hline Smoking history, years & & & & 0.434 \\
\hline$<10$ & 34 & 25 & 9 & \\
\hline$\geq 10$ & 47 & 38 & 9 & \\
\hline Tumor differentiation, grade & & & & 0.591 \\
\hline $\mathrm{I}-\mathrm{II}$ & 45 & 34 & 11 & \\
\hline III-IV & 36 & 29 & 7 & \\
\hline TNM classification, stage & & & & 0.026 \\
\hline $\mathrm{I}$ & 22 & 13 & 9 & \\
\hline II & 31 & 28 & 3 & \\
\hline III+IV & 28 & 22 & 6 & \\
\hline Metastasis & & & & 0.011 \\
\hline No & 33 & 21 & 12 & \\
\hline Yes & 48 & 42 & 6 & \\
\hline
\end{tabular}

The median expression level of miR-320 was used as a cutoff point to divide all patients into low and high expression groups.

no. ab106062; Abcam, Cambridge, MA, USA) and mouse anti-GAPDH monoclonal antibody (1:1,000 dilution; cat no. ab125247; Abcam). The membranes were then incubated with goat anti-mouse $\mathrm{IgG}$ horseradish peroxidase-conjugated secondary antibody (1:5,000 dilution; cat. no. ab6789; Abcam) was applied to the membranes for $1 \mathrm{~h}$ at room temperature. The protein blots were visualized with ECL reagents (Pierce; Thermo Fisher Scientific, Inc.), imaged using a FluorChem imaging system (ProteinSimple, San Jose, CA, USA) and normalized to GADPH. Protein bands were normalized to GAPDH and analyzed using the AlphaEase FC2 software (Alpha Innotech, San Leandro, CA, USA).

Luciferase assay. The luciferase assays were performed to determine whether FAS was a direct target of miR-320. NSCLC cells were plated in a $24-w e l l$ plate at $40-50 \%$ confluency and were transfected with the luciferase reporter plasmid (synthesized by GenePharma Co., Ltd.), miR-320 mimics or NC in a 12-well plate using Lipofectamine 2000 according to the manufacturer's protocol. After $48 \mathrm{~h}$, the activities of firefly and Renilla luciferases were measured with the Dual-Luciferase Reporter Assay system (Promega Corporation, Madison, WI, USA). The firefly luciferase activity was normalized to the Renilla luciferase activity. The wells were assessed in triplicate for each treatment group.

Statistical analysis. Data are presented as the mean \pm standard deviation, and compared using SPSS software (version 11.0;
SPSS, Inc., Chicago, IL, USA). One-way analysis of variance followed by a least significant differences test was conducted to analyze the data. $\mathrm{P}<0.05$ was considered to indicate a statistically significant difference.

\section{Results}

miR-320 expression in human NSCLC tissues and cell lines. To examine the function of miR-320 in NSCLC, miR-320 expression was analyzed by RT-qPCR. As demonstrated in Fig. 1A and B, the level of miR-320 was significantly downregulated in NSCLC tissue samples when compared with matched NATs $(\mathrm{P}=0.002)$. The expression level of miR-320 in NSCLC cell lines and non-tumorigenic bronchial epithelium BEAS-2B cells was also detected. As demonstrated in Fig. 1C, miR-320 expression level was also significantly decreased in $\mathrm{H} 23$ and H522 cells compared with BEAS-2B cells $(\mathrm{P}=0.001)$. These results indicate that miR-320 may be important during lung carcinogenesis.

Association between miR-320 expression level and clinicopathological features of patients with NSCLC. Statistical analysis was performed to determine whether the expression level of miR-320 was associated with the clinicopathological features of patients with NSCLC. The results demonstrated that the expression level of miR-320 was significantly associated with the TNM classification $(\mathrm{P}=0.028)$ and metastasis $(\mathrm{P}=0.016)$. However, no correlation was identified between the 
A

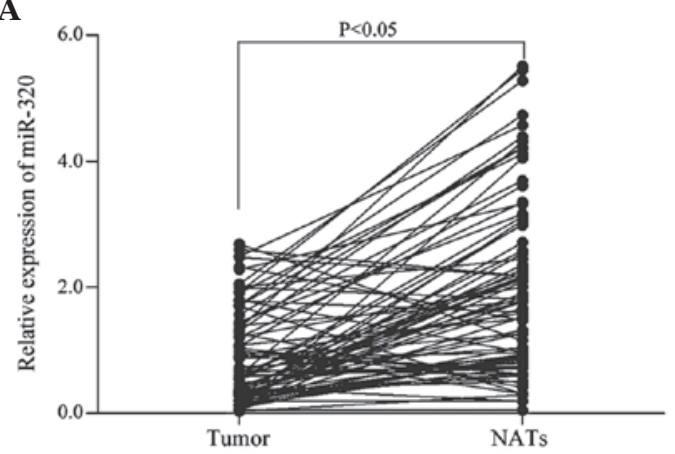

B

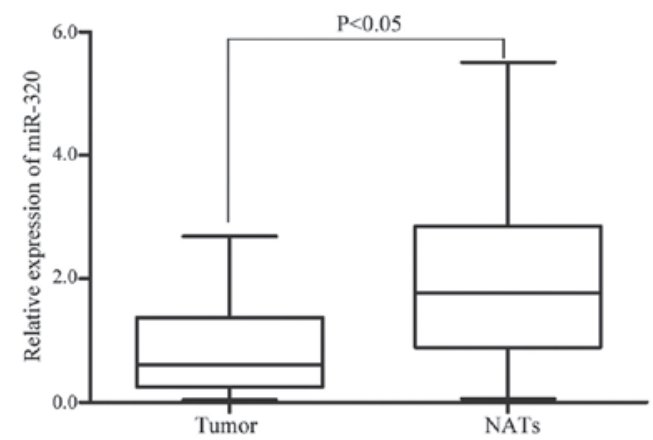

C

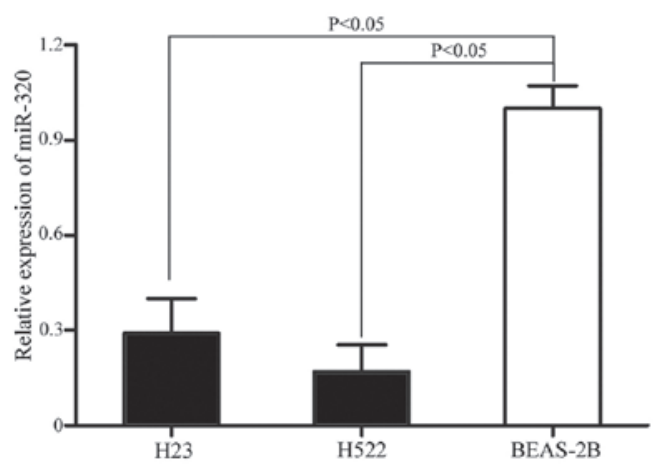

Figure 1. Expression of miR-320 in NSCLC tissues and cell lines (A and B) miR-320 was significantly downregulated in NSCLC tissue samples compared with matched NATs. (C) miR-320 expression level was significantly decreased in $\mathrm{H} 23$ and H522 cells compared with non-tumorigenic bronchial epithelium BEAS-2B cells. NSCLC, non-small cell lung cancer; miR, microRNA; NATs, normal adjacent tissues.

miR-320 expression level and the other clinicopathological features (gender, age, smoking history and tumor differentiation).

miR-32O suppresses cell proliferation in H23 and H522 cells. The effect of miR-320 on NSCLC cell proliferation was measured by MTT assay. It was demonstrated that the absorbance in $\mathrm{H} 23(\mathrm{P}=0.008)$ and H522 $(\mathrm{P}=0.019)$ cells transfected with miR-320 was significantly decreased when compared with the NC group $(\mathrm{P}<0.05$; Fig. 2$)$. This verified that miR-320 inhibits the proliferation of $\mathrm{H} 23$ and $\mathrm{H} 522$ cells.

miR-320 inhibits cell migration and invasion in $\mathrm{H} 23$ and $\mathrm{H} 522$ cells. The effect of miR-320 on NSCLC cell migration and invasion was measured using Transwell apparatus. As demonstrated in Fig. 3, overexpression of miR-320 significantly reduced the migration and invasion ability of $\mathrm{H} 23(\mathrm{P}=0.021$ for migration, 0.025 for invasion) and $\mathrm{H} 522(\mathrm{P}=0.015$ for migration; $\mathrm{P}=0.020$ for invasion) cells compared with the $\mathrm{NC}$ group $(\mathrm{P}<0.05)$. These results indicate that miR-320 may be involved in reducing the migration and invasion potential of NSCLC cells in vitro.

miR-320 directly targets FAS. FAS protein is important for cancer proliferation and metastasis, and was predicted to be a direct target gene of miR-320 (Fig. 4A); luciferase assays were performed to verify this. As demonstrated in Fig. 4B, miR-320 mimics significantly inhibited the luciferase activity of the wild type but not the mutant FAS 3' UTR constructs in H23 $(\mathrm{P}=0.034)$ and $\mathrm{H} 522$ cells $(\mathrm{P}=0.018)$.

Furthermore, western blot analysis was performed to determine the protein expression level of FAS in H23 and H522 cells following transfection with miR-320. The results of the current study demonstrate that the expression level of FAS was significantly inhibited in miR-320 mimic-transfected $\mathrm{H} 23(\mathrm{P}=0.021)$ and H522 $(\mathrm{P}=0.028)$ cells compared with cells transfected with $\mathrm{NC}(\mathrm{P}<0.05$; Fig. $4 \mathrm{C})$. These results demonstrate that FAS is a direct target gene of miR-320 in vitro.

\section{Discussion}

Increasing evidence indicates that the aberrant expression of miRNAs is a characteristic of multiple types of malignancy, including lung cancer $(13,22)$. The expression of miR-320 has been observed to be downregulated in various types of human cancer, including breast cancer, oral squamous cell carcinoma (OSCC), colon cancer, acute myelogenous leukemia, osteosarcoma and glioma (23-28). However, to the best of our knowledge, no previous studies have investigated the expression of miR-320 in lung cancer. The present study demonstrated that miR-320 was significantly downregulated in NSCLC tissue samples and cell lines. Furthermore, the expression of miR-320 was significantly associated with the TNM classification and presence of metastasis. These results indicate that miR-320 may be important in NSCLC.

miR-320 has previously been demonstrated to be a tumor suppressor during tumorigenesis and progression in multiple types of cancer. In colon cancer, upregulation of miR-320 was demonstrated to inhibit cell growth, cell cycle, migration and invasion, whereas downregulation of miR-320 had the opposite effect on these biological processes (24). Additionally, it was demonstrated that overexpression of miR-320 enhanced the sensitivity of human colon cancer cells to fluorouracil and oxaliplatin by targeting forkhead box M1 in vitro (24). In OSCC, miR-320 was demonstrated to suppress tumor angiogenesis via downregulation of neuropilin 1 (26). Cheng et al (27) also reported that miR-320 inhibits osteosarcoma cell proliferation by targeting FAS. In human glioma, miR-320 decreased cell growth by directly targeting E2F transcription factor 1 (28). However, to the best of our knowledge, no previous studies have investigated the function of miR-320 in lung cancer. The present study demonstrated that miR-320 inhibits NSCLC cell proliferation, migration and invasion. The current study increased the knowledge of the functions of miR-320 in cancer. These findings indicate that miR-320 performs an essential function in these forms of cancer, and may have the potential to be developed as an anticancer therapeutic agent. 

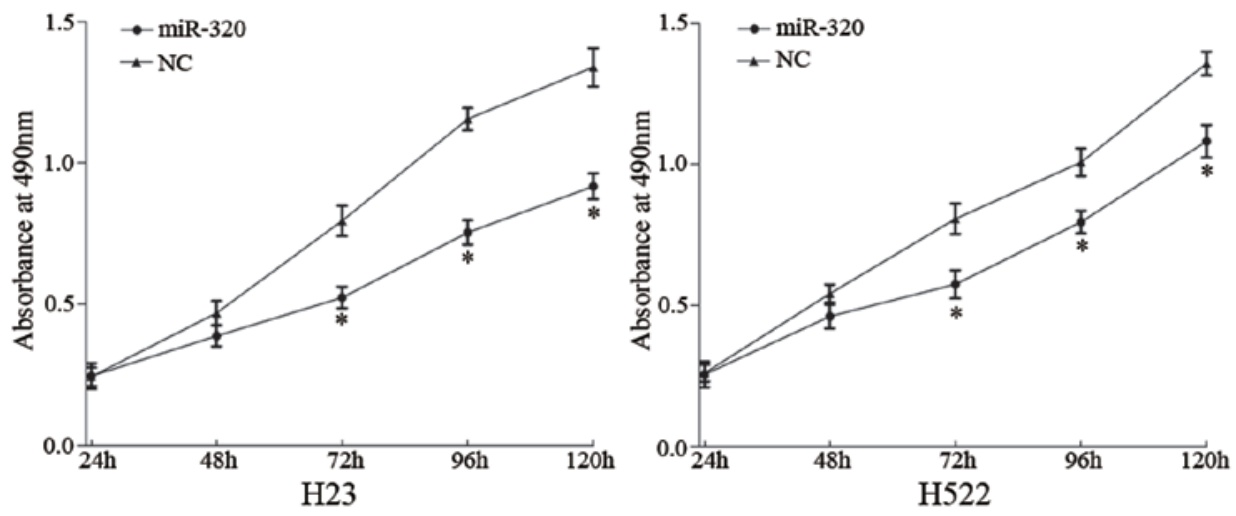

Figure 2. miR-320 inhibited cell proliferation in non-small cell lung cancer cells. The proliferation of H23 and H522 cells was determined by 3-(4,5-dimethylthiazol-2-yl)-2,5-diphenyltetrazolium bromide assay after transfection with miR-320 or NC. "P<0.05, compared with NC. miR, microRNA; NC, negative control.

A

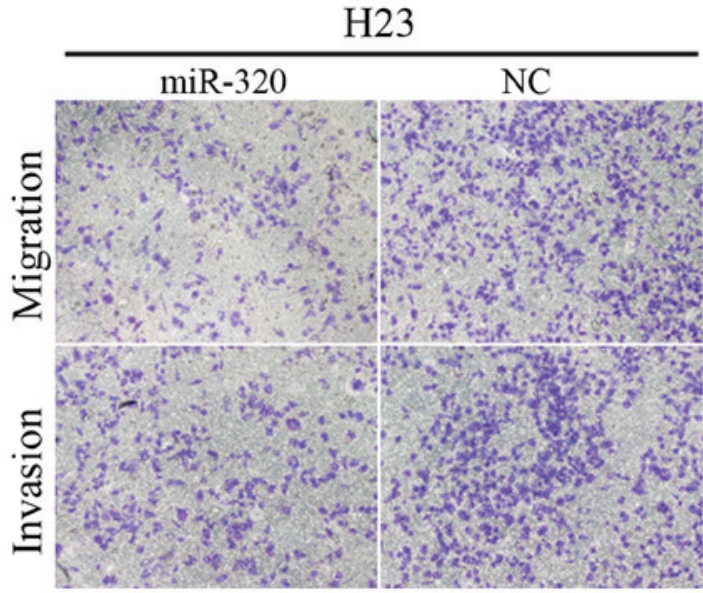

H522

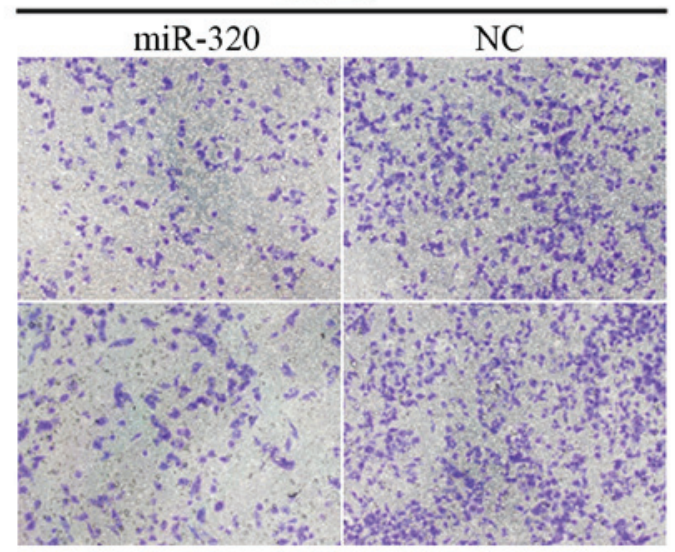

B
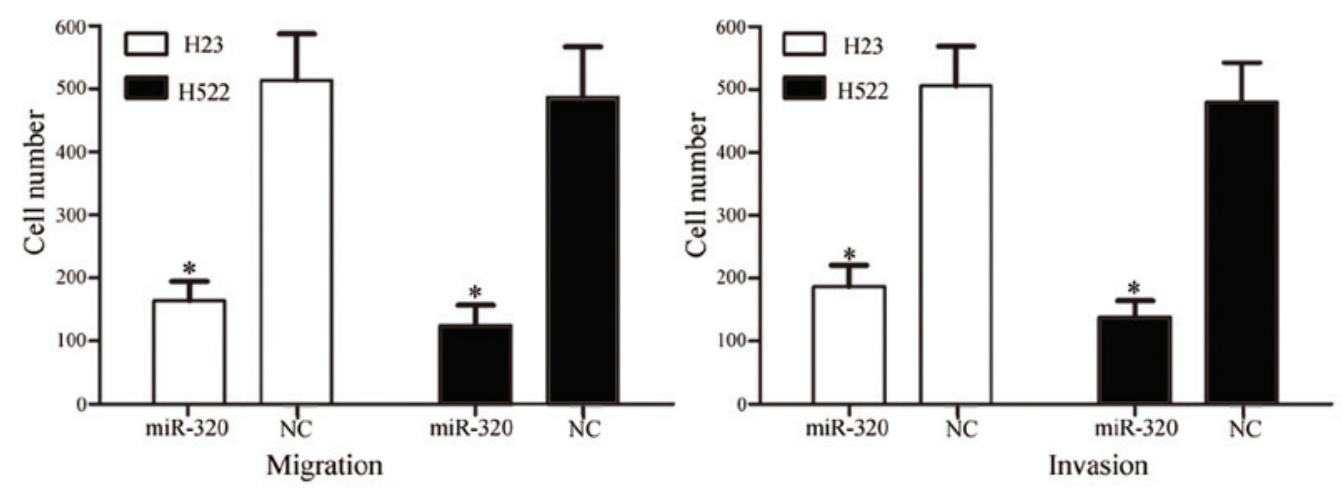

Figure 3. miR-320 inhibited cell migration and invasion in non-small cell lung cancer cells. The migration and invasion abilities of H23 and H522 cells transfected with miR-320 or NC were measured using Transwell chambers with an 8- $\mu \mathrm{m}$ pore polycarbonate membrane. (A) Microscopic images at x200 magnification, (B) quantification of migration and invasion. ${ }^{*} \mathrm{P}<0.05$, compared with NC. Magnification, $\mathrm{x} 200$. miR, microRNA; NC, negative control.

Identification of miR-320 target genes is essential for understanding its mechanism in lung carcinogenesis and for the development of novel targeted therapies. The current study successfully demonstrated that FAS is a direct target gene of miR-320. Bioinformatics software (TargetScan) predicted that FAS was a direct target mRNA of miR-320 and luciferase assays demonstrated that miR-320 directly interacts with FAS 3' UTR. Furthermore, manipulation of miR-320 expression in NSCLC cell lines decreased the expression of FAS at the protein level. These findings suggest that miR-320 acts as a tumor suppressor in NSCLC by targeting FAS.

FAS, a multifunctional enzymatic complex, catalyzes the formation of palmitate from acetyl-coenzyme A and malonyl-coenzyme A (29). The endogenous FAS is expressed at very low levels in normal human tissues (30). However, increasing studies have demonstrated that the expression level of FAS is highly upregulated and involved in cancer proliferation and metastasis in various types of human tumor, including 
A
FAS 3' UTR (WT)
hsa-miR-320
5' GCAUUAGaUagauUacuCCCGCU 3'
IIIIIII
FAS 3' UTR (Mut)
3' AAAAgCUgGguUgagAGGGCGA $5^{\prime}$
II I ।
$5^{\prime}$ GCAUUAgaUagaUUaCUCAAACU $3^{\prime}$

B
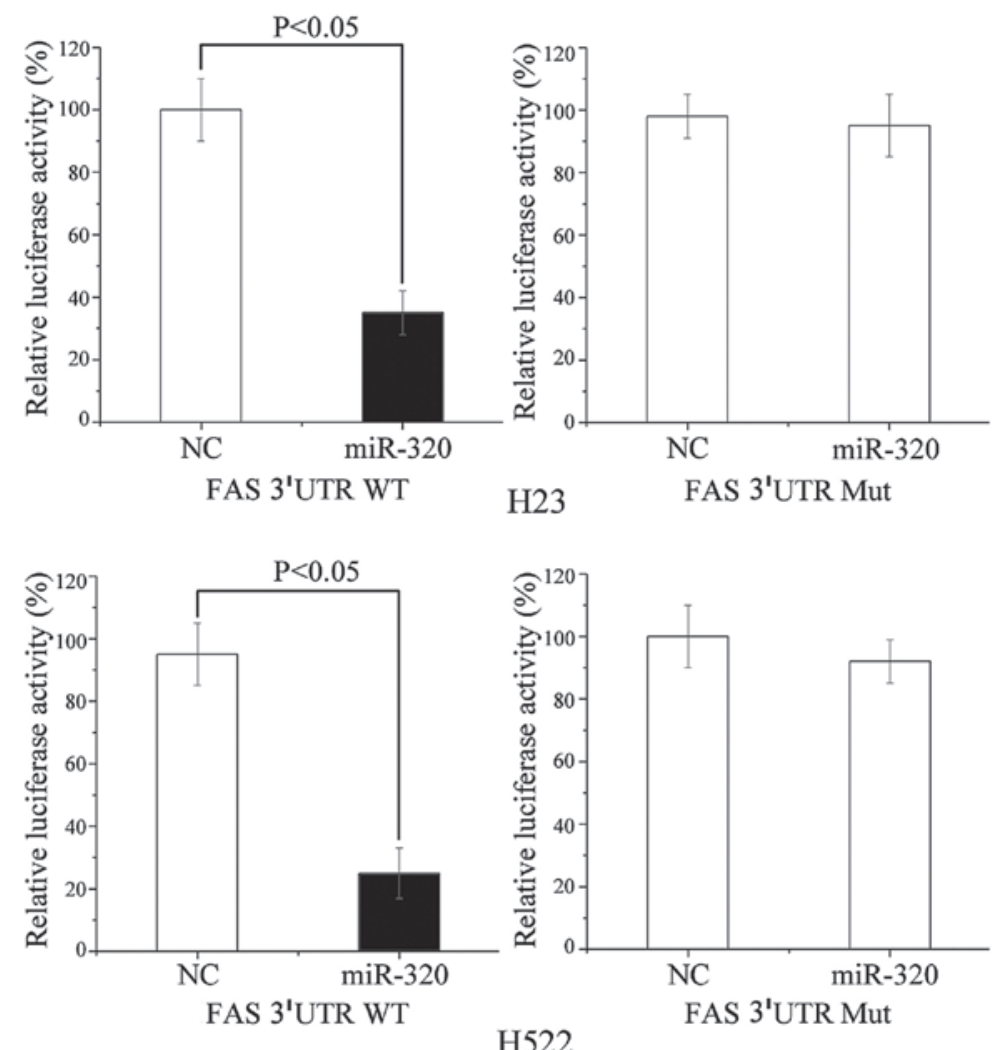

C
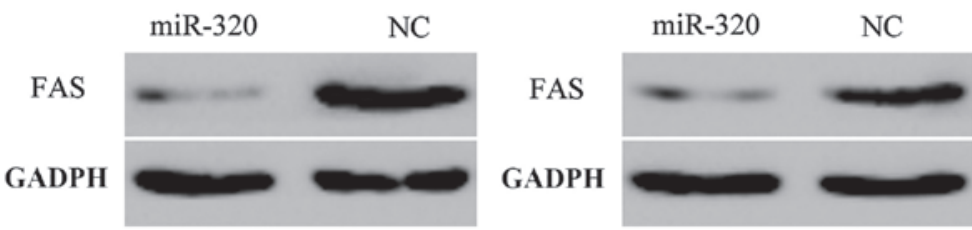

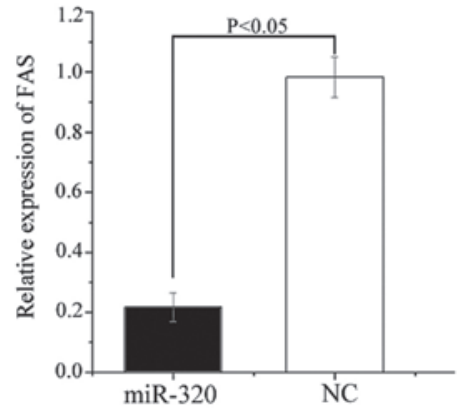

$\mathrm{H} 23$

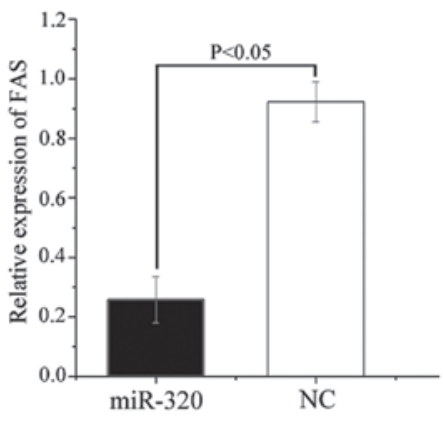

H522

Figure 4. miR-320 directly targeted FAS. (A) TargetScan analysis demonstrated that FAS mRNA contained an miR-320 seven-nucleotide seed sequence of the FAS 3' UTR. (B) The luciferase activity was significantly decreased in H23 and H522 cells co-transfected with miR-320 mimic and FAS 3' UTR WT. (C) FAS was significantly downregulated at protein level in miR-320 mimic-transfected H23 and H522 cells compared with the NC. FAS, fatty acid synthase; UTR, untranslated region; miR, microRNA; WT, wild type; Mut, mutant; NC, negative control.

breast, colorectal, prostate, bladder, ovarian, esophageal, gastric and lung cancer, oral carcinoma, thyroid cancer and endometrial carcinoma, and also in mesothelioma, nephroblastoma, retinoblastoma, soft tissue sarcomas, melanoma and hepatocellular carcinoma (31-33). FAS was also previously reported to be correlated with various clinicopathological features of cancer. For example, overexpression of FAS in NSCLC was reported to be significantly associated with bone metastasis (34). These studies suggested that targeting FAS may present as a therapeutic approach. 
FAS has previously been demonstrated to be regulated by multiple miRNAs in multiple types of cancer, including lung cancer. miR-601, miR-10b and miR-663 are involved in the biology of lung cancer via direct or indirect regulation of FAS (35-37). In osteosarcoma, miR-142-3p and miR-320 have been reported to act as tumor suppressors by regulation of FAS $(27,38)$. Previous studies demonstrated that miR-424 and miR-195 regulate FAS to inhibit osteosarcoma cell migration and invasion $(39,40)$. In colorectal and breast cancer, miR-196b and miR-21 modulate cell apoptosis by repressing FAS expression $(41,42)$. In gastric cancer, altered miR-106a expression levels exert oncogenic effects in gastric carcinogenesis by targeting FAS (43). In prostate cancer, miR-185 and miR-342 have been demonstrated to decrease cell proliferation, migration and invasion by inhibiting FAS indirectly (44). In hepatocellular carcinoma, restoration of miR-449 suppresses cell proliferation by downregulating FAS (45). In the present study, overexpression of miR-320 in NSCLC cell lines demonstrated that miR-320 inhibits cell proliferation, migration and invasion via downregulation of FAS. Taken together, these results indicate that miR-320 may act as a tumor suppressor by inhibiting the oncogenic activity of FAS.

In conclusion, this was the first study, to the best of our knowledge, to demonstrate that miR-320 is downregulated in NSCLC, and is significantly associated with the TNM classification and metastasis. It was also demonstrated that miR-320 contributes to cell proliferation, migration and invasion by directly targeting FAS in NSCLC. The identification of FAS as a candidate target gene of miR-320 may provide an understanding of the potential carcinogenic mechanisms in NSCLC. These findings have therapeutic implications and may be exploited for developing treatment strategies for NSCLC.

\section{References}

1. Siegel R, Ma J, Zou Z and Jemal A: Cancer statistics, 2014. CA Cancer J Clin 64: 9-29, 2014.

2. Siegel RL, Miller KD and Jemal A: Cancer statistics, 2015. CA Cancer J Clin 65: 5-29, 2015

3. Yang X, Chen BB, Zhang MH and Wang XR: MicroRNA-126 inhibits the proliferation of lung cancer cell line A549. Asian Pac J Trop Med 8: 239-242, 2015

4. Ni T, Mao G, Xue Q, Liu Y, Chen B, Cui X, Lv L, Jia L, Wang Y and Ji L: Upregulated expression of ILF2 in non-small cell lung cancer is associated with tumor cell proliferation and poor prognosis. J Mol Histol 46: 325-335, 2015.

5. Peters S, Adjei AA, Gridelli C, Reck M, Kerr K and Felip E ESMO Guidelines Working Group: Metastatic non-small-cell lung cancer (NSCLC): ESMO Clinical Practice Guidelines for diagnosis, treatment and follow-up. Ann Oncol 23 (Suppl 7): vii56-vii64, 2012.

6. Zhang T, Zhang DM, Zhao D, Hou XM, Liu XJ, Ling XL and Ma SC: The prognostic value of osteopontin expression in non-small cell lung cancer: A meta-analysis. J Mol Histol 45: 533-540, 2014.

7. Leidinger P, Galata V, Backes C, Stähler C, Rheinheimer S, Huwer H, Meese E and Keller A: Longitudinal study on circulating miRNAs in patients after lung cancer resection. Oncotarget 6: 16674-16685, 2015.

8. Cai J, Fang L, Huang Y, Li R, Yuan J, Yang Y, Zhu X, Chen B, Wu J and Li M: miR-205 targets PTEN and PHLPP2 to augment AKT signaling and drive malignant phenotypes in non-small cell lung cancer. Cancer Res 73: 5402-5415, 2013.

9. Pisters KM, Evans WK, Azzoli CG, Kris MG, Smith CA, Desch CE, Somerfield MR, Brouwers MC, Darling G, Ellis PM, et al: Cancer care Ontario and American society of clinical oncology adjuvant chemotherapy and adjuvant radiation therapy for stages I-IIIA resectable non small-cell lung cancer guideline. J Clin Oncol 25: 5506-5518, 2007.
10. Fiori ME, Barbini C, Haas TL, Marroncelli N, Patrizii M, Biffoni M and De Maria R: Antitumor effect of miR-197 targeting in p53 wild-type lung cancer. Cell Death Differ 21: 774-782, 2014

11. Hatley ME, Patrick DM, Garcia MR, Richardson JA, Bassel-Duby R, van Rooij E and Olson EN: Modulation of K-Ras-dependent lung tumorigenesis by MicroRNA-21. Cancer Cell 18: 282-293, 2010.

12. Seike M, Goto A, Okano T, Bowman ED, Schetter AJ, Horikawa I, Mathe EA, Jen J, Yang P, Sugimura H, et al: MiR-21 is an EGFR-regulated anti-apoptotic factor in lung cancer in never-smokers. Proc Natl Acad Sci USA 106: 12085-12090, 2009.

13. Chen C, Zhao Z, Liu Y and Mu D: microRNA-99a is downregulated and promotes proliferation, migration and invasion in non-small cell lung cancer A549 and H1299 cells. Oncol Lett 9: 1128-1134, 2015.

14. Ambros V: The functions of animal microRNAs. Nature 431: 350-355, 2004.

15. Bartel DP: MicroRNAs: Genomics, biogenesis, mechanism, and function. Cell 116: 281-297, 2004.

16. Broderick JA and Zamore PD: MicroRNA therapeutics. Gene Ther 18: 1104-1110, 2011.

17. Guo H, Ingolia NT, Weissman JS and Bartel DP: Mammalian microRNAs predominantly act to decrease target mRNA levels. Nature 466: 835-840, 2010.

18. Mitchell PS, Parkin RK, Kroh EM, Fritz BR, Wyman SK, Pogosova-Agadjanyan EL, Peterson A, Noteboom J, O'Briant KC, Allen A, et al: Circulating microRNAs as stable blood-based markers for cancer detection. Proc Natl Acad Sci USA 105: 10513-10518, 2008.

19. Chen X, Ba Y, Ma L, Cai X, Yin Y, Wang K, Guo J, Zhang Y, Chen J, Guo X, et al: Characterization of microRNAs in serum: A novel class of biomarkers for diagnosis of cancer and other diseases. Cell Res 18: 997-1006, 2008.

20. Kent OA and Mendell JT: A small piece in the cancer puzzle: microRNAs as tumor suppressors and oncogenes. Oncogene 25: 6188-6196, 2006

21. Livak KJ and Schmittgen TD: Analysis of relative gene expression data using real-time quantitative PCR and the 2(-Delta Delta C(T)) Method. Methods 25: 402-408, 2001.

22. Ling DJ, Chen ZS, Zhang YD, Liao QD, Feng JX, Zhang XY and Shi TS: MicroRNA-145 inhibits lung cancer cell metastasis. Mol Med Rep 11: 3108-3114, 2015

23. Yan LX, Huang XF, Shao Q, Huang MY, Deng L, Wu QL, Zeng YX and Shao JY: MicroRNA miR-21 overexpression in human breast cancer is associated with advanced clinical stage, lymph node metastasis and patient poor prognosis. RNA 14: 2348-2360, 2008.

24. Wan LY, Deng J, Xiang XJ, Zhang L, Yu F, Chen J, Sun Z, Feng M and Xiong JP: miR-320 enhances the sensitivity of human colon cancer cells to chemoradiotherapy in vitro by targeting FOXM1. Biochem Biophys Res Commun 457: 125-132, 2015.

25. Schaar DG, Medina DJ, Moore DF, Strair RK and Ting Y: miR-320 targets transferrin receptor 1 (CD71) and inhibits cell proliferation. Exp Hematol 37: 245-255, 2009.

26. Wu YY, Chen YL, Jao YC, Hsieh IS, Chang KC and Hong TM: miR-320 regulates tumor angiogenesis driven by vascular endothelial cells in oral cancer by silencing neuropilin 1. Angiogenesis 17: 247-260, 2014.

27. Cheng C, Chen ZQ and Shi XT: MicroRNA-320 inhibits osteosarcoma cells proliferation by directly targeting fatty acid synthase. Tumour Biol 35: 4177-4183, 2014.

28. Sun JY, Xiao WZ, Wang F, Wang YQ, Zhu YH, Wu YF, Miao ZL and Lin YC: MicroRNA-320 inhibits cell proliferation in glioma by targeting E2F1. Mol Med Rep 12: 2355-2359, 2015.

29. Lupu R and Menendez JA: Targeting fatty acid synthase in breast and endometrial cancer: An alternative to selective estrogen receptor modulators? Endocrinology 147: 4056-4066, 2006.

30. Weiss L, Hoffmann GE, Schreiber R, Andres H, Fuchs E, Körber E and Kolb HJ: Fatty-acid biosynthesis in man, a pathway of minor importance. Purification, optimal assay conditions, and organ distribution of fatty-acid synthase. Biol Chem Hoppe Seyler 367: 905-912, 1986.

31. Chen J, Zhuang D, Cai W, Xu L, Li E, Wu Y and Sugiyama K: Inhibitory effects of four plants flavonoids extracts on fatty acid synthase. J Environ Sci (China) 21 (Suppl 1): S131-S134, 2009.

32. Liu ZL, Wang G, Peng AF, Luo QF, Zhou Y and Huang SH: Fatty acid synthase expression in osteosarcoma and its correlation with pulmonary metastasis. Oncol Lett 4: 878-882, 2012. 
33. Menendez JA and Lupu R: Fatty acid synthase and the lipogenic phenotype in cancer pathogenesis. Nat Rev Cancer 7: 763-777, 2007.

34. Wang Y, Zhang XR, Fu J, Tan W and Zhang W: Prognostic value of expression of FASE, HER-2/neu, bcl-2 and p53 in stage I non-small cell lung cancer. Zhonghua Zhong Liu Za Zhi 26 : 369-372, 2004 (In Chinese).

35. Liu ZY, Zhang GL, Wang MM, Xiong YN and Cui HQ: MicroRNA-663 targets TGFB1 and regulates lung cancer proliferation. Asian Pac J Cancer Prev 12: 2819-2823, 2011.

36. Ohdaira H, Nakagawa $\mathrm{H}$ and Yoshida K: Profiling of molecular pathways regulated by microRNA 601. Comput Biol Chem 33: 429-433, 2009

37. Huang J, Sun C, Wang S, He Q and Li D: microRNA miR-10b inhibition reduces cell proliferation and promotes apoptosis in non-small cell lung cancer (NSCLC) cells. Mol Biosyst 11: 2051-2059, 2015

38. Yang YQ, Qi J, Xu JQ and Hao P: MicroRNA-142-3p, a novel target of tumor suppressor menin, inhibits osteosarcoma cell proliferation by down-regulation of FASN. Tumour Biol 35: 10287-10293, 2014

39. Mao JH, Zhou RP, Peng AF, Liu ZL, Huang SH, Long XH and Shu Y: microRNA-195 suppresses osteosarcoma cell invasion and migration in vitro by targeting FASN. Oncol Lett 4: 1125-1129, 2012.
40. Long XH, Mao JH, Peng AF, Zhou Y, Huang SH and Liu ZL: Tumor suppressive microRNA-424 inhibits osteosarcoma cell migration and invasion via targeting fatty acid synthase. Exp Ther Med 5: 1048-1052, 2013.

41. Wu MF, Yang J, Xiang T, Shi YY and Liu LJ: miR-21 targets Fas ligand-mediated apoptosis in breast cancer cell line MCF-7. J Huazhong Univ Sci Technolog Med Sci 34: 190-194, 2014.

42. Mo JS, Alam KJ, Kang IH, Park WC, Seo GS, Choi SC, Kim HS, Moon HB, Yun KJ and Chae SC: MicroRNA 196B regulates FAS-mediated apoptosis in colorectal cancer cells. Oncotarget 6: 2843-2855, 2015 .

43. Wang Z, Liu M, Zhu H, Zhang W, He S, Hu C, Quan L, Bai J and $\mathrm{Xu}$ N: miR-106a is frequently upregulated in gastric cancer and inhibits the extrinsic apoptotic pathway by targeting FAS. Mol Carcinog 52: 634-646, 2013.

44. Li X, Chen YT, Josson S, Mukhopadhyay NK, Kim J, Freeman MR and Huang WC: MicroRNA-185 and 342 inhibit tumorigenicity and induce apoptosis through blockade of the SREBP metabolic pathway in prostate cancer cells. PLoS One 8: e70987, 2013.

45. Zhang H, Feng Z, Huang R, Xia Z, Xiang G and Zhang J: MicroRNA-449 suppresses proliferation of hepatoma cell lines through blockade lipid metabolic pathway related to SIRT1. Int J Oncol 45: 2143-2152, 2014. 